\title{
The psychological study on the methods of moral education
}

\author{
Li Zhao \\ Moral Education Centre, Canvard College, Beijing Technology and Business \\ University, Beijing, China \\ lilyzhao349@sohu.com
}

Keywords: psychological states, psychological needs, methodological guidance, moral education.

\begin{abstract}
At present, the task of Ideological and moral education for college students is very arduous, and many problems of the college students are closely related to their psychological states. Students' mental health is the basis and content of Ideological and moral education. Students' psychological acceptance is the premise and effect of the Ideological and moral education. In this paper, from the understanding of students' psychological states, I try to know their needs and then use some psychological theories to provide a methodological guidance for the Ideological and moral education.
\end{abstract}

\section{Introduction}

In the rapid development of social economy, the social environment is changing rapidly today, the campus is also no longer a quiet "ivory tower". Extremely events often happened in the university campus, such as college students suicided, campus violence, and in the daily life, the college students often cut school with no reasons and come to class late but leave early. They also play phones in class and cheat in the examinations. As a teacher, I must think about that. Although the ideological and moral education has been carried out, these still are happening. And to explore the various problems of college students, I find out that all these have a great relationship with the psychological states of college students.

Students' mental health is the basis and important content of Ideological and moral education. The students truly accept the theory of the education and do what they know which is the precondition and effect of the ideological and moral education. And it is necessary to study the method of the ideological and moral education from the psychological needs of students. At the same time, psychology also provides method guidance for the ideological and moral education.

As a result, we have done a survey ${ }^{1}$ among the students to try to understand the students' psychological status and their attitudes of the current ideological and moral education. We also want to know the effect of the education.

2 First, adapting to the college life is very important for the college students, and is also the basis of the Ideological and moral education.

From the investigation, we found that $45 \%$ of the college students thought that they were mentally vulnerable and also under a lot of pressure, which may be the important reasons for the current college students' Dutch acts, campus violence and other issues. Mental health is the foundation of education and is also one of the contents of education. Therefore, we should pay more attention to the mental health of students first, For the college freshmen, they are facing a new environment, they must adapt all, new environment, new friends and so on. Many freshmen may

\footnotetext{
1 A random questionnaire survey was conducted within the whole college. 200 questionnaires were sent out, 174 were withdrawn, and 150 questionnaires were valid
} 
show different degrees of adjustment disorder. This period should be paid special attention to by the school and teachers. Let the students realize their own problems and have energy to face the problems, then gradually adapt to the new college life. In the teaching process, through the analysis of theory, case study, class discussion, let students realize the importance of adaptation, because many students cannot adapt to the new life, and not to face and solve the problems, which may lead to ultimately irreparable tragedy. We should help the students to face the problems and find the solve ways. In the survey the students were asked, "when you feel unhappy and very depressed, what would you do?" About 50\% students chose to be alone. Only 1\% of the students chose to go to the psychological consultation for help.

At this point, we should establish a perfect psychological counseling room, hiring professional counselors and popularize them, let the students know where to get help. As a teacher, we should be their friends. When they are in trouble, they are willing to connect us.

\section{Second, the students' psychological acceptance is the embodiment of the precondition and effect of the ideological and moral education.}

From the investigation, we found that $89.06 \%$ of the students think that the moral quality of college students is very important, but when they were asked if they would cheat in the test, $48 \%$ of students chose the one that if they cannot be found out, they will do. We may conclude that students have the desire to accept moral education and improve their own qualifications, but moral education has not been internalized into actual behavior. What are the students most worried and in pressure in college is that life is boring and they have no clear goals for their future. The students have great psychological needs in personal growth, but for the courses of Ideological and moral education now, $31 \%$ of the students think that they have no harvest. In our college, we have carried out some reforms and attempts on the course of Ideological and moral cultivation and legal basis. But the survey shows that $88 \%$ of the students do not know much about the reform. Therefore the effect of our moral education is not optimistic.

Why the students are not interested in the current curriculum? in the survey, 33\% of the students think that because the course content is boring, and less contact with their real lives. And more theories are taught in class, the students need to recite them before the exam, they cannot accept well through this way. Therefore, as a teacher, we should pay more attention to the reality, what we teach should be close to the students' life and perspective. Combined with the reality of the case and multi topic associated with the students, guide students to think, let the students find out problems, and try to solve the problems, we should try to change the students prejudices against the ideological and moral courses and stimulate students' thinking interest and pleasure.

In the choice of practice or theoretical courses, $81 \%$ of students prefer the practical courses, they think that practical courses are more useful, they can have a deeper understanding during the practices. Therefore, we need to strengthen the practice courses, practice methods should be diversified, to meet the needs of more students.

When I visited Chaoyang University of Technology in Taiwan, I learned that the university won the first school of moral education characteristics in 2014. Then we learned that there is no cleaner in the university, and all labors, including cleaning the toilets are done by the students completely, this is one part of their moral education, labor course is compulsory but zero credits. Their president also stressed that they don't want to save the cost of running schools by not hiring cleaners, the senior students lead the freshmen, and the senior students have service fees, in this process, their responsibility and cooperation are enhanced, they not only truly realize that the environment is on everyone, but also know how to respect the work of others. And for the senior students, in the process, their organizational and leadership capabilities are enhanced. We think this is a very successful practice, the students truly achieve more, it is worth for us to learn. 


\section{Third, the moral psychology inspires me and I think we can use psychological methods in the ideological and moral education to improve the effectiveness of Ideological and moral education.}

Moral psychology is an important topic that philosophers and psychologists from China and foreign countries pay attention to, and it is the combination of ethics and psychology. ${ }^{2}$ Moral psychology provides a new perspective for the study of individual moral behavior. J. Lester, the American psychologist, also proposed a moral psychological model to explore the individual moral behavior. He believes that the formation of individual moral behavior goes through four psychological processes, that is, interpreting situations, making judgments, moral choices, and implementing behaviors. From another point of view, it can be understood that human moral behavior is a process of internalization, which is an individual psychological process.

1 Pay attention to the influence of environment on the moral education and create a big moral education environment. Social psychology holds the theory that human beings are creatures of the environment, the French philosopher Sutter believe that we human beings " are creatures of circumstances at first ", because the situation is shaping us, many possibilities of us in the future are decided by it and we will not be independent of its existence. ${ }^{3}$ Human behavior is influenced by others and the situations, which is the focus of social psychology research. So when discussing some problems in class, we should consider the social environment, For example, once we discussed about the"XiaoYueyue" event in Guangzhou. It's not meaningful to blame people for their low moral sense and indifference, perhaps each of us is one of those who didn't give help. We should analysis why people wouldn't try to help when they saw the injured little girl, not one person but dozens of people passed indifferently.

On this issue, social psychologists have put forward the theory of "dispersed responsibility", This is the specific application of the theory of social psychology, we may find the essence of the problem with the psychological theory, and then try to solve the problem with students. At the same time, the content of Ideological and moral education is also permeated.

Meanwhile we can get the inspiration that we should pay attention to the role of environment in Ideological and moral education, pay attention to the penetration of disciplines and the construction of school environment. All the teachers are teachers of moral education. Moral education is reflected in all aspects of life and learning, and it is the way to improve personal growth and moral quality. Integrity education, for example, which is reflected in all aspects of the school, and is related to all subjects. In our college, we once made rules that if the student cheated in the exams, he would fail the course of "Ideological and moral cultivation and legal basis". Let students realize that moral education is not just to study a course and to pass the exam, then they can get the credit and finish the course. Moral education is reflected in all aspects of life and learning, and it is the way to improve personal growth and moral quality.

2 The traditional teaching models take teachers as the main part in class. Referring to the way of psychological consultation, through the exchange and communication with students, we permeate the content of education to them and change the traditional preaching method.

The traditional method of Ideological and moral education is mainly based on the teaching theory of teachers, and the students accept passively. It is easy for students to feel boring and uninteresting, which will inevitably affect the effect of education. The nature of psychological counseling is "the process of psychological counselors helping those who seek help to solve all kinds of psychological problems." 4 In the process of psychological counseling, the Counselor's position is on the "assistance", in other words, the success of psychological counseling depends largely on whether

\footnotetext{
2 "Western moral psychology" Yang Shaogang, Shanghai Education Press; October 1, 2007, first edition;

3 "Social psychology" David Myers , translated by Hou Yubo Le Guoan Zhang Zhiyong et, Posts and

Telecommunications Press, Eighth Edition

4 <Psychological consultant> National Publishing House
} 
the person who seeks help has the attitude and behavior of active participation. Similarly, in the process of Ideological and moral education, teachers should change their posture in the education. Teachers should change their roles, learn to play as the psychological counselors, let students become the subject of curriculum, teachers play the role of assistance. At the same time, on the methods, we also need to change, instead of teaching more theory, we may discuss, communicate with the students. Teachers gradually penetrate the content of education to the students and they learn actively and take in the class. Then we can reach the purpose of education.

3 According to the social learning theory, we should pay attention to the cultivation of students' behavior. Social learning theory is proposed by American social psychologist Bandura based on the previous studies, focusing on the role of observational learning and self-regulation in the initiation of human behavior. He emphasized that human behavior was acquired. Social learning theory holds that there are three main mechanisms for human learning: connection, reinforcement and imitation. The purpose of Ideological and moral education is to internalize the contents of education into behaviors, and ultimately to reflect on behaviors.

In the process of teaching, we can consciously use the three mechanisms; connection is mainly used in the process of knowledge interpreting, let the students understand the reasons of the behaviors and have an ability in problem solving and analysis, then find the mechanism behind the behaviors. Reinforcement is the core of social learning theory. It refers to the fact that people learned a specified behavior because it is often accompanied by pleasant results, meeting certain needs, or avoiding some unpleasant consequences. In practice, it is reward or punishment, that is to encourage positive behaviors and ignore or punish the negative behaviors. The college should be strict in the school discipline and school spirit, and be impartial in meting rewards and punishments. It will be a great guiding effect on students' behavior. Imitation means that people can learn social attitudes and behaviors by observing other people's attitudes and behaviors. At this point, teachers should set an example, in the process of teaching practice, every word and action of the teachers may become the object of imitation for the students. Besides, we should pay attention to the influence of mass media and to the students' spare time. We should enrich the campus culture such as showing excellent films and dramas, through a variety of ways to enrich students' spare time, and then affect the students' behavior.

The above, from the specific psychological theory, I find some methods and put them to use in ideological and moral education.

We have made some progresses, we will keep trying and looking for more ways to improve the effect of ideological and moral education.

In brief, this paper attempts to explore the method of Ideological and moral education from the psychological point of view. By examining the psychological status and psychological needs of students, we can get the students' attitudes and opinions on the current ideological and moral education curriculum. Through the theoretical study and research, we explore the connection of psychology and ethics, and then find some reasonable and effective methods for the ideological and moral education, make moral education more effective, hoping to achieve the purpose of education.

\section{References}

[1] "Western moral psychology" Yang Shaogang, Shanghai Education Press; October 1, 2007, first edition

[2] "Social psychology" David Myers , translated by Hou Yubo Le Guoan Zhang Zhiyong et, Posts and Telecommunications Press, Eighth Edition

[3] "Psychological consultant” National Publishing House, July,2005

[4] “Principles of ethics”Wang Haiming, Peking University press, August 2001, first edition; 